\title{
Efeito da fotoperiodicidade na taxa de prenhez em ratos isogênicos (F344)
}

\author{
Effect of photoperiodicity in the pregnancy rate of isogenic rats (F344)
}

\author{
Alexandre Bastos Baptista ${ }^{\mathrm{I}}$ Erika Lissa Morita ${ }^{\mathrm{I}}$ Cristiane Carlin Passos $^{\mathrm{I}}$ \\ Amanda Olivotti Ferreira ${ }^{\mathrm{I}}$ Flávio Ribeiro Alves ${ }^{\mathrm{II}}$ Alexandre José Alves ${ }^{\mathrm{III}}$ \\ Maria Angélica Miglino ${ }^{\text {I }}$ Ricardo Romão Guerra ${ }^{\text {III }}$
}

\section{RESUMO}

O uso de animais isogênicos apresenta grandes vantagens experimentais, como uniformidade fenotipica $e$ genotípica (reduzindo o número de animais em experimentos) e histocompatibilidade, permitindo, assim, o acúmulo de informações e a repetibilidade dos experimentos. A linhagem isogênica de Rattus norvegicus Fischer 344 existe há 90 anos, entretanto pouco se sabe sobre as razões de seu baixo índice reprodutivo. O presente estudo demonstrou que ratos Fischer F344 são fotorresponsivos quanto à reprodução, tendo seus indices de prenhezes acrescidos com o aumento do fotoperiodo. Os melhores indices são obtidos quando os machos são submetidos a 14 horas de luz e fêmeas a 16 horas de luz, indicando dimorfismo sexual na fotorresponsividade.

Palavras-chave: fotoperíodo, Rattus norvegicus, reprodução, Fischer 344, indice reprodutivo.

\section{ABSTRACT}

The use of isogenic animals presents great experimental advantages, as phenotypic and genotypic uniformity (reducing the number of experimental animals) and histocompatibility, thus allowing, the accumulation of information, and the repeatability of the experiments. The isogenic strain of Rattus norvegicus Fischer 344 has existed for 90 years, however the reasons of its low reproductive index are not knew. The present study has demonstrated that Fischer F344 rats are photoresponsive regarding reproduction, having improved its pregnancy index with the increase of the photoperiod. The best indexes were achieved when the males had been submitted to 14 hours of light and females to 16 hours of light, indicating sexual dimorphism in photoresponsivity.
Key words: photoperiod, Rattus norvegicus, reproduction, Fischer 344, reproductive index.

\section{INTRODUÇÃO}

Animais isogênicos são uma importante ferramenta na pesquisa científica, desde o desenvolvimento das suas primeiras linhagens que datam do princípio do século XX. O Rato Fischer F344 foi a primeira linhagem isogênica de animais de laboratório, desenvolvida na Universidade de Columbia em 1918. Desde então, mantém-se como a principal linhagem isogênica de ratos utilizada em laboratórios ao redor do mundo, tendo sido utilizada em aproximadamente 400 pesquisas de duração superior a dois anos pelo National Cancer Institute/National Toxicology Program (NCI/NTP) americano. O material resultante dessas pesquisas contém dados sobre mais de 100.000 ratos F344, incluindo oito milhões de lâminas histológicas (FESTING, 1998). O uso de animais isogênicos apresenta grandes vantagens experimentais, como uniformidade fenotípica e genotípica (reduzindo o número de animais necessários em experimentos), histocompatibilidade, desenvolvimento de modelos animais; permitindo, assim, o acúmulo de informações e a repetibilidade de experimentos.

Apesar do imenso conhecimento acumulado sobre a linhagem F344 nos últimos 90 anos,

IDepartamento de Cirurgia, Faculdade de Medicina Veterinária e Zootecnia (FMVZ), Universidade de São Paulo (USP), São Paulo, SP, Brasil. E-mail: alexbbap@gmail.com. *Autor para correspondência.

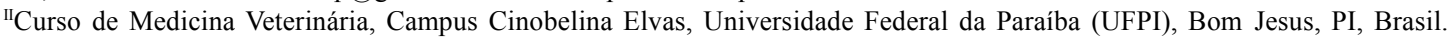

IIIDepartamento de Ciências Veterinárias, Centro de Ciências Agrárias, Universidade Federal da Paraíba (UFPB), Areia, PB, Brasil. 
pouco se sabe sobre as razões da relativa dificuldade que sua reprodução apresenta. Em geral, o Rattus norvegicus é considerado espécie não fotoperiódica, reproduzindo-se com grande facilidade durante o ano todo (HEIDEMAN \& SYLVESTER, 1997). Entretanto, recentemente, alguns estudos apontaram a influência do fotoperíodo no desenvolvimento sexual da F344. SHOEMAKER \& HEIDEMAN (2002) concluíram que a fotoperiodicidade afeta o desenvolvimento reprodutivo da F344, considerando para isso que o tamanho testicular, as vesículas seminais e o desenvolvimento puberal são inibidos pelo fotoperíodo de 8 horas (h). Animais fotorresponsivos requerem manejo específico para reprodução bem sucedida. Dessa forma, o presente estudo tem como objetivo analisar a influência de diferentes fotoperíodos em machos e fêmeas F344 sobre o índice de prenhez, de forma a determinar qual o melhor protocolo para um bem sucedido manejo reprodutivo da F344.

\section{MATERIAL E MÉTODOS}

Animais

Ratos Fischer F344 foram obtidos e mantidos no biotério SPF do Instituto de Química da USP (IQ USP). Foram acondicionados em caixas plásticas forradas com maravalha, na qual foram colocadas diariamente $50 \mathrm{~g}$ de ração e água ad libitum. A cama foi trocada a cada cinco dias e os ambientes tinham a luminosidade controlada por um timer e lâmpada fluorescente de 20 watts.

\section{Delineamento experimental}

Fêmeas com idade média de quatro meses foram agrupadas em caixas contendo três animais cada. Machos com idade entre 6-7 meses foram mantidos em caixas individuais e colocados nas caixas das fêmeas no fim da tarde para pernoite e retirados na manhã seguinte, quando foram realizados os lavados vaginais com o auxilio de pipeta de Pasteur e soro fisiológico. Os lavados foram analisados ao microscópio óptico sem corantes para verificação da presença de espermatozóides, indicativa de acasalamento. Essas fêmeas eram monitoradas e as prenhezes eram confirmadas pela presença de embriões no útero materno.

As combinações de diferentes fotoperíodos aos quais machos e fêmeas foram submetidos foram testadas em 9 diferentes grupos: grupo 1 - machos fotoperíodo $12 \mathrm{~h}$ e fêmeas fotoperíodo $12 \mathrm{~h}$; grupo 2 machos fotoperíodo $12 \mathrm{~h}$ e fêmeas fotoperíodo $14 \mathrm{~h}$; grupo 3 - machos fotoperíodo $12 \mathrm{~h}$ e fêmeas fotoperíodo 16h; grupo 4 - machos fotoperíodo $16 \mathrm{~h}$ e fêmeas fotoperíodo $12 \mathrm{~h}$; grupo 5 - machos fotoperíodo $16 \mathrm{~h}$ e fêmeas fotoperíodo 16h; grupo 6 - machos fotoperíodo $14 \mathrm{~h}$ e fêmeas fotoperíodo $16 \mathrm{~h}$; grupo 7 - machos fotoperíodo $14 \mathrm{~h}$ e fêmeas fotoperíodo $12 \mathrm{~h}$; grupo 8 machos fotoperíodo $16 \mathrm{~h}$ e fêmeas fotoperíodo $14 \mathrm{~h}$; e grupo 9 - machos fotoperíodo $16 \mathrm{~h}$ e fêmeas fotoperíodo $14 \mathrm{~h}$.

Análise estatística

Para análise estatística, por tratar-se de variável qualitativa dicotômica nominal, comparamos as proporções de taxas de prenhez entre cada grupo individualmente em relação a cada um dos outros grupos (duas proporções), mediante o teste do quiquadrado $(\mathrm{P}<0,05)$.

\section{RESULTADOS}

As combinações de diferentes fotoperíodos aos quais machos e fêmeas foram submetidos foram testadas. Abaixo, encontram-se os dados sumarizados ("N" refere-se às possibilidades de acasalamento de cada grupo, ou seja, número de fêmeas expostas à machos): Grupo $1(\mathrm{~N}=67)$ : fêmeas em fotoperíodo de $12 \mathrm{~h} \times$ machos em fotoperíodo de $12 \mathrm{~h}$ :

3 prenhezes $(4,5 \%)$; grupo $2(\mathrm{~N}=27)$ : fêmeas em fotoperíodo de $14 \mathrm{~h}$ x machos em fotoperíodo de $12 \mathrm{~h}: 4$ prenhezes $(14,8 \%)$; grupo $3(\mathrm{~N}=31)$ : fêmeas em fotoperíodo de $16 \mathrm{~h}$ x machos em fotoperíodo de $12 \mathrm{~h}: 7$ prenhezes $(22,6 \%)$; grupo $4(\mathrm{~N}=27)$ : fêmeas em fotoperíodo de $12 \mathrm{~h}$ x machos em fotoperíodo de $14 \mathrm{~h}: 4$ prenhezes $(14,8 \%)$; grupo $5(\mathrm{~N}=28)$ : fêmeas em fotoperíodo de $14 \mathrm{~h} \times$ machos em fotoperíodo de $14 \mathrm{~h}: 3$ prenhezes $(10,7 \%)$; grupo $6(\mathrm{~N}=27)$ : fêmeas em fotoperíodo de $16 \mathrm{~h} \times$ machos em fotoperíodo de $14 \mathrm{~h}$ : 11 prenhezes $(40,7 \%)$; Grupo $7(\mathrm{~N}=28)$ : fêmeas em fotoperíodo de $12 \mathrm{~h}$ x machos em fotoperíodo de $16 \mathrm{~h}: 3$ prenhezes $(10,7 \%)$; grupo $8(\mathrm{~N}=28)$ : fêmeas em fotoperíodo de $14 \mathrm{~h}$ x machos em fotoperíodo de 16h: 3 prenhezes $(10,7 \%)$; e grupo $9(\mathrm{~N}=27)$ : fêmeas em fotoperíodo de $16 \mathrm{~h}$ x machos em fotoperíodo de $16 \mathrm{~h}: 2$ prenhezes $(7,4 \%)$. $\mathrm{N}$ total $=290$.

Os índices de prenhezes obtidos pelos diferentes grupos (porcentagem de prenhez $\mathrm{x}$ possibilidade de acasalamento) estão representados abaixo (Figura 1).

Encontramos diferenças significativas $(\mathrm{P}<0,05)$ entre o grupo 1 "machos e fêmeas submetidos ao fotoperíodo de $12 \mathrm{~h}$ " e o Grupo 3 "machos sob fotoperíodo de $12 \mathrm{~h}$ e fêmeas sob fotoperíodo de $16 \mathrm{~h}$ ", sendo maior o índice de prenhez no grupo 3.

O grupo 6 "machos sob fotoperíodo de $14 \mathrm{~h}$ e fêmeas sob fotoperíodo de $16 \mathrm{~h}$ ” apresentou diferença 


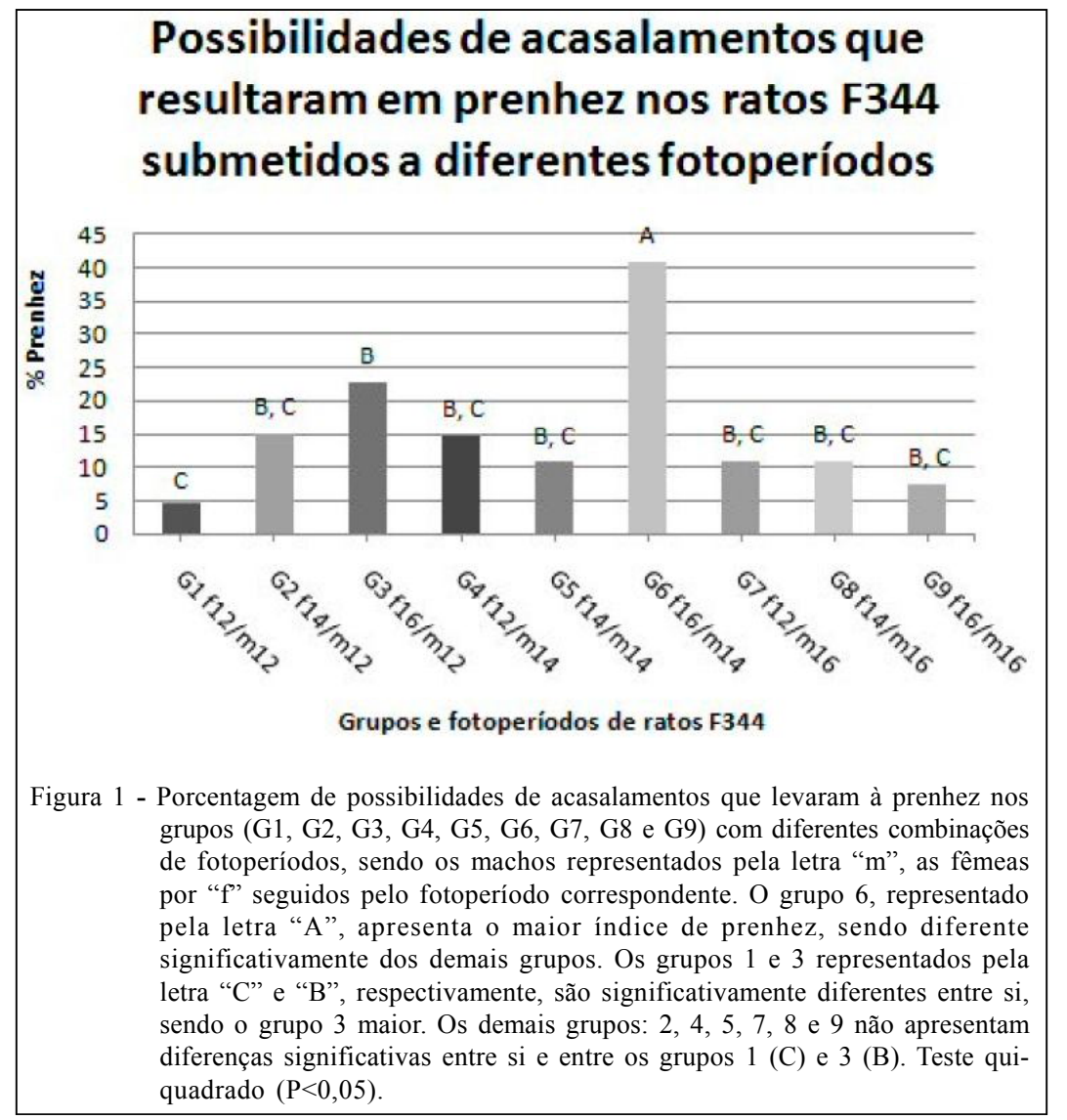

significativa com todos os outros grupos estudados, sendo o grupo que apresentou a maior taxa de prenhez. Os demais grupos: 2, 4, 5, 7, 8 e 9 não apresentaram diferenças significativas entre si e entre os grupos 1 e 3 .

\section{DISCUSSÃO}

Animais são expostos às variações ambientais como oferta de alimento, água, abrigo, que são dependentes do clima das diversas estações do ano, principalmente aqueles que vivem em zonas temperadas. Animais fotorresponsivos se adaptam melhor a essas variações, alterando seu comportamento, morfologia e fisiologia de acordo com a luminosidade (NELSON et al., 1990).

A glândula pineal é responsável por secretar a melatonina, durante a noite, e indicar ao organismo a atual estação do ano, sendo a secreção menor durante o verão (dias longos) e maior durante o inverno (dias curtos). Sua ação na reprodução varia de acordo com a espécie, ou seja, em uma espécie de dias curtos, como ovelhas, a melatonina estimula a secreção de gonadotrofinas e LH (hormônio luteinizante) aumentando a frequência de sua secreção pulsátil
(KARSCH et al., 1984). Já em espécies de dias longos, como hamsters sírios, a melatonina inibe a secreção de FSH (hormônio folículo estimulante), LH e gonadotrofinas (TAMARKIN et al., 1976).

Em geral, o Rattus norvegicus é considerado uma espécie reprodutivamente não fotoperiódica, reproduzindo-se com grande facilidade durante o ano todo. Pouca atenção, até a última década, foi dada ao fato de que diferentes linhagens apresentam significativas variações em seus índices reprodutivos (LORINCZ et al., 2001), dentre elas a linhagem F344, utilizada no presente projeto. Essa linhagem apresenta baixos índices reprodutivos (SHOEMAKER \& HEIDEMAN, 2002), pelo menos em fotoperíodo convencionalmente utilizado em biotérios (ciclo de luz/ sombra de 12 horas), fato esse observado em nosso estudo.

Visto isso, alguns estudos apontaram a influência do fotoperíodo no desenvolvimento sexual da F344. SHOEMAKER \& HEIDEMAN (2002) concluíram que a fotoperiodicidade afeta $\mathrm{o}$ desenvolvimento reprodutivo da F344, considerando para isso que o volume testicular, o das vesículas seminais e o desenvolvimento puberal são inibidos pelo 
fotoperíodo de $8 \mathrm{~h}$. Já o fotoperíodo de $16 \mathrm{~h}$ aumenta o volume testicular em comparação com o fotoperíodo normalmente utilizado em biotérios (12h). Apesar dos resultados obtidos em tal experimento, nenhuma pesquisa sobre a influência do fotoperiodismo nos índices reprodutivos foi realizada.

Estudos em hamsters sírios, considerados fotoperiódicos, expostos a curto fotoperíodo $(10 \mathrm{~h}$ de luz e 14 de escuro) demonstram uma diminuição da secreção de gonadotrofinas e andrógenos testiculares, regressão dos testículos e eventual perda de comportamento copulatório em machos (PRENDERGAST et al., 2002) e aciclicidade em fềmeas, indicando mudanças gonadais fotoderivadas (SEEGAL \& GOLDMAN, 1975; HAUSER \& BENSON, 1986). Outro experimento com hamsters sírios demonstrou que, ao serem expostos a curtos fotoperíodos, a expressão de receptores andrógenos e SRC-1 (receptor coactivator-1), um coativador nuclear de testosterona, diminui em determinadas áreas do cérebro, alterando assim a sensibilidade à testosterona, o que pode contribuir para as alterações sazonais na resposta aos esteróides (TETEL et al., 2004).

$\mathrm{O}$ curto fotoperíodo também diminui as concentrações plasmáticas de LH e FSH, um evento que é independente de esteróides (BITTMAN et al., 1996), mas potencializado pela testosterona, que assume um efeito supressor do LH e FSH sérico em animais submetidos a dias curtos, além de perder sua potência como ativador da libido e da espermatogênese (MIERNICKI et al., 1990).

Apesar de essas pesquisas demonstrarem que a baixa exposição à luz diminui os índices reprodutivos em algumas espécies, nenhum estudo mostra qual seria o fotoperíodo ideal para melhorar os índices reprodutivos dos animais. Sendo assim, também não existem pesquisas que indiquem qual fotoperíodo seria o ótimo para a reprodução da linhagem F344, linhagem essa de grande importância em experimentos que requerem homogeneidade entre os espécimes ou naqueles que se procura a compatibilidade imunológica entre eles.

No presente estudo, obtivemos baixos índices de prenhezes quando machos e fêmeas foram submetidos ao fotoperíodo de $12 \mathrm{~h}(4,5 \%)$, o padronizado pelos biotérios. Ao se aumentar o fotoperíodo ao qual as fêmeas eram normalmente submetidas, foram aumentados também os índices de prenhezes. Ao se aumentar o fotoperíodo ao qual os machos eram submetidos para $14 \mathrm{~h}$, mantendo as fêmeas em $12 \mathrm{~h}$, também houve um aumento do número de prenhez (14,8\%). Entretanto, observou-se um decréscimo acentuado quando os machos foram submetidos à luminosidade de $16 \mathrm{~h}(7,1 \%)$, sugerindo uma limitação reprodutiva do macho submetido a dias muito longos. Entretanto, as fêmeas submetidas ao fotoperíodo de $16 \mathrm{~h}$ apresentaram os melhores índices reprodutivos $(22,6 \%$ e $40,7 \%$ respectivamente, para machos com $12 \mathrm{e} 14 \mathrm{~h}$ ). O dimorfismo sexual na resposta ao aumento de fotoperíodo pode estar relacionado às diferentes respostas neuroendócrinas a estímulos em cada gênero (ANISHCHENKO et al., 1988).

SHOEMAKER \& HEIDEMAN (2002) demonstraram que o volume testicular de ratos F344 submetidos a baixo fotoperíodo ( $8 \mathrm{~h}$ ) é menor quando comparado aos ratos sob fotoperíodo convencional (12h), e que ratos sob fotoperíodo de $16 \mathrm{~h}$ têm o volume testicular aumentado. Apesar de os autores não testarem a implicação da variação do volume testicular nos índices reprodutivos desses machos, provavelmente haja uma relação positiva. Eles também relataram que as diferenças encontradas no volume testicular vão diminuindo com o aumento da idade do animal. Sendo que, com aproximadamente 16 semanas, essa diferença inexiste para os fotoperíodos testados $(8,12$ e $16 \mathrm{~h}$ de luz) pelos autores.

Em nosso experimento, verificamos maior eficiência reprodutiva em machos $\mathrm{F} 344$ sob fotoperíodo de $14 \mathrm{~h}$, fotoperíodo esse não avaliado por SHOEMAKER \& HEIDEMAN (2002), mas que possivelmente levaria a um aumento do volume testicular. Nossos resultados também demonstram que há fotorresponsividade em ratos machos F344 adultos, pelo menos em fotoperíodo de $14 \mathrm{~h}$, uma vez que os ratos utilizados em nosso experimento podem ser considerados adultos (tinham entre 24-28 semanas). Esse resultado entra em desacordo com os obtidos por SHOEMAKER \& HEIDEMAN (2002). Os autores citados rejeitam que haja fotorresponsividade em ratos F344 adultos.

Dessa forma, o presente estudo demonstrou que a linhagem de ratos Fischer F344 é fotorresponsiva quanto à reprodução, tendo seus índices de prenhezes acrescidos com o aumento do fotoperíodo, pelo menos no que concerne às fêmeas, uma vez que a taxa de prenhez, quando os machos foram submetidos à fotoperíodo de 16h, diminuiu. Essa fotorresponsividade da F344 se deve, provavelmente, a uma seleção acidental de animais mais fotorresponsivos durante a criação dessa linhagem, já que o $\boldsymbol{R}$. norvegiccus apresenta uma variação individual à resposta ao fotoperíodo, ou devido a alguma mutação gênica que restaurou parcialmente tal característica (LORINCZ et al., 2001). O estudo também indicou que a otimização dos índices de prenhezes foi obtida utilizando-se machos submetidos a 14 horas de luz e fêmeas a $16 \mathrm{~h}$ de luz, indicando dimorfismo sexual na fotorresponsividade. 
Concluímos, assim, que os ratos isogênicos Fischer 344 são fotorresponsivos. No presente estudo, foram observados melhores índices reprodutivos quando fêmeas eram submetidas a um fotoperíodo de $16 \mathrm{~h}$ e machos a um fotoperíodo de $14 \mathrm{~h}$.

\section{AGRADECIMENTOS}

À Fundação de Amparo à Pesquisa do Estado de São Paulo (FAPEPS), pelo apoio financeiro (processo n. 2008/ 00051-6).

\section{COMITÊ DE ÉTICA}

Projeto aprovado pela Comissão de Bioética da Faculdade de Medicina Veterinária e Zootecnia da Universidade de São Paulo (USP) sob protocolo n. 1377/2008, em 23 de abril de 2008 .

\section{REFERÊNCIAS}

ANISHCHENKO, T.G. et al. Sexual dimorphism of the stress response with a normal and altered photoperiod. Biulleten' Eksperimental'noi Biologii I Meditsiny, v.106, p.21-23, 1988. Disponível em: <http://www.springerlink.com/content/ tv326581726u9124/>. Acesso em: 17 out. 2010. doi: 10.1007/ BF00834641.

BITTMAN, E.L. et al. Effects of photoperiod and androgen on pituitary function and neuropeptide staining in Siberian hamsters. American Journal of Physiology, v.271, p.6472, 1996. Disponível em: <http://www.ncbi.nlm.nih.gov/ pubmed/8760205>. Acesso em: 17 out. 2010. PMDI: 8760205 [PubMed - indexed for MEDLINE].

HAUSER, U.E.; BENSON, B. Rapid cessation of estrous cydicity and depressed castration response in short photoperiod-treated, inbred LSH/SsLak hamsters. Biology of Reproduction, v.35, p.276-281, 1986. Disponível em: <http://www.biolreprod.org/ content/35/2/276.full.pdf $>$. Acesso em: 17 out. 2010. doi: 10.1095/biolreprod35.2.276.

HEIDEMAN, P.D.; SYLVESTER, C.J. Reproductive photoresponsiveness in unmanipulated male Fischer 344 laboratory rats. Biology of Reproduction, v.57, p.134-138, 1997. Disponível em: <http://www.biolreprod.org/content/57/ 1/134.full.pdf $>$. Acesso em: 17 out. 2010. doi: 10.1095/ ?biolreprod57.1.134.

FESTING, M.F.W. Inbred strains of rats and their characteristics. Leicester: Mouse Genome Informatics, The Jackson Laboratory, 1998. 221p. Disponível em: <http:// www.informatics.jax.org/external/festing/rat/docs/F344.shtml>. Acesso em: 17 out. 2010.

KARSCH, F.J. et al. Neuroendocrine basis of seasonal reproduction. Recent Progress in Hormone Research, v.40, p.185-232, 1984. Disponível em: <http://www.ncbi.nlm.nih.gov/ pubmed/6385166>. Acesso em: 17 out. 2010. PMID: 6385166 [PubMed - indexed for MEDLINE].

LORINCZ, A.M. et al. Genetic variation in photoperiodism among naturally photoperiodic rat strains. American Journal of Physiology. Regulatory, Integrative and Comparative Physiology, v.281, p.1817-1824, 2001. Disponível em: <http:// ajpregu.physiology.org/cgi/content/full/281/6/R1817>. Acesso em: 17 out. 2010. PMID: 11705766 [PubMed - indexed for MEDLINE]. INIST-CNRS, Cote INIST: 670 E, 35400009933236.0090.

MIERNICKI, M.W. et al. Short photoperiods affect male hamster sociosexual behaviors in the presence and absence of testosterone. Physiology Behavior, v.47, p.95-106, 1990. Disponível e $\mathrm{m}:<\mathrm{ht} \mathrm{tp}: / / \mathrm{w}$ w w. s c i e n c e di rect.co m/ science? ob=ArticleURL\& udi=B6T0P-482RGYYSH\&_user $=10 \&$ coverDate $=01 \% 2 \mathrm{~F} 31 \% 2 \mathrm{~F} 1990 \&$ rdoc $=1 \&$ fm $\mathrm{t}=$ high \&_orig $=$ search\&_origin $=$ search\&_sort $=\mathrm{d} \&$ _docanchor $=\& \mathrm{~V}$ iew $=\mathrm{c} \&$ acct $=\mathrm{C} 000050221$ \& version $=1 \&$ urlVersion $=0$ \& userid $=10 \&$ $\mathrm{md} 5=9 \mathrm{fe} 071 \mathrm{de} 0 \mathrm{c} 42 \mathrm{bbd} 35 \mathrm{a} 0 \mathrm{f} 18 \mathrm{f} 73 \mathrm{efeccef} \&$ searchtype $=\mathrm{a}>$. Acesso em: 17 out. 2010. doi:10.1016/0031-9384(90)90046-7.

NELSON, R.J. et al. Mecanisms of seasonal cycles of behavior. Annual Review of Psychology, v.41, p.81-108, 1990. Disponível em: <http://www.annualreviews.org/doi/abs/10.1146/ annurev.ps.41.020190.000501>. Acesso em: 17 out. 2010. doi: 10.1146 .

PRENDERGAST, B.J. et al. Hormones, brain and behavior. New York: Academic, 2002. 156p. Disponível em: <http:// www.elsevierdirect.com/brochures/hormones/>. Acesso em: 20 out. 2010 .

SEEGAL, R.F.; GOLDMAN, B.D. Effects of photoperiod on cyclicity and serum gonadotropins in the Syrian hamster. Biology of Reproduction, v.12, p.223-231, 1975. Disponível em: <http:/ /www.biolreprod.org/content/12/2/223.full.pdf $+\mathrm{html}>$. Acesso em: 17 out. 2010 . doi: $10.1095 /$ ?biolreprod12.2.223.

SHOEMAKER, M.B.; HEIDEMAN, P.D. Reduced body mass, food intake, and testis size in response to short photoperiod in adult F344 rats. BMC Physiology, v.2, p.11, 2002. Disponível em: <http://www.biomedcentral.com/1472-6793/2/11/>. Acesso em: 17 out. 2010 . doi: 10.1186/1472-6793-2-11.

TAMARKIN, L. et al. Regulation of serum gonadotropins by photoperiod and testicular hormone in the Syrian hamster. Endocrinology, v.99, p.1528-1533, 1976. Disponível em: $<$ http://endo.endojournals.org/cgi/content/abstract/99/6/1528>. Acesso em: 17 out. 2010. doi:10.1210/endo-99-6-1528.

TETEL, M.J. et al. Photoperiodic regulation of androgen receptor and steroid receptor coactivator -1 in Siberian hamster brain. Brain Research. Molecular Brain Research, v.131, p.79-87, 2004. Disponível em: <http://www.sciencedirect.com/ science? ob=ArticleURL\& udi=B6T07-4DF4D4P$1 \&$ user $=10 \&$ \&coverDate $=11 \% 2 \mathrm{~F} 24 \% 2 \mathrm{~F} 2004 \&$ rdoc $=1 \&$ fm $\mathrm{t}=\mathrm{high} \&$ orig $=$ search \& origin $=$ search \& sort $=\mathrm{d} \&$ docanchor $=\& \mathrm{vi}$ 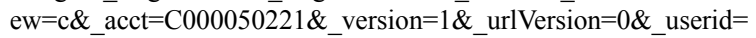 $10 \& \mathrm{md} 5=\mathrm{d} 2 \mathrm{f} 8 \mathrm{~d} 1 \mathrm{acc} 796 \mathrm{ab} 4 \overline{7} \mathrm{a} 2 \mathrm{~b} 9738 \mathrm{efd}$ e3036\&searchtype $=\mathrm{a}>$. Acesso em: 17 out. 2010. doi:10.1016/j.molbrainres.2004.08.009. 